\title{
3D FINITE ELEMENT ANALYSIS OF ECAP PROCESSING ROUTES INFLUENCE ON STRAIN HOMOGENEITY
}

\author{
${ }^{1}$ Jure KROLO, ${ }^{1}$ Branimir LELA, ${ }^{1}$ Joze EVIĆ, ${ }^{2}$ Nikolay BIBA \\ ${ }^{1}$ Faculty of Electrical Engineering, Mechanical Engineering, and Naval Architecture, Split, Croatia, EU, \\ jkrolo@fesb.hr \\ ${ }^{2}$ MICAS Simulations Limited, Temple Court, Oxford, United Kingdom
}

https://doi.org/10.37904/metal.2021.4116

\begin{abstract}
In the last three decades, equal channel angular pressing (ECAP) process is used for extreme microstructural refinement of the metal materials which leads to improvement of the mechanical and physical properties. Using ECAP method significant strains can be imposed into the material. However, for practical use, homogeneous distribution of the strain is very important. Usually, ECAP processing routes are applied to distribute strain homogeneously inside processed workpiece. In this research 3D finite element simulations analysis was used to investigate the influence of four main ECAP processing routes and in total four ECAP passes on strain homogeneity distribution through workpiece volume and selected cross-sections. Simulations results after four ECAP passes indicated that strain homogeneity through whole workpiece volume was highest for route $A$ and lowest for route $\mathrm{C}$. However, at cross-section $30 \mathrm{~mm}$ from the workpiece back end, route $\mathrm{C}$ and $\mathrm{Bc}$ provided the highest strain homogeneity. Results indicated that route $C$ and $B c$ are more adequate if only a homogeneous part of the workpiece material will be used in a possible application. However, if the aim is to use the whole workpiece material volume, route $A$ is more appropriate. This was achieved because route $A$ is more efficient in deformation of the workpiece back end at channel intersection which was indicated with strain inhomogeneity index for the cross-section $5 \mathrm{~mm}$ apart from the workpiece back end.
\end{abstract}

Keywords: Finite element simulation, ECAP process, Aluminium, ECAP routes, Strain homogeneity

\section{INTRODUCTION}

In the last three decades, severe plastic deformation methods (SPD) are developed to produce bulk nanostructured or ultrafine grained materials with a unique combination of mechanical and physical properties $[1,2]$. One of the most popular severe plastic deformation methods is equal channel angular pressing (ECAP). The main reasons for ECAP wide experimental studies and application are the possibility of processing fairly large billets, relatively simple procedure, preservation of initial cross-section, reasonable homogeneity through most of the pressed billet, and potential for use in commercial metal processing procedures [3]. Due to the complexity of SPD processing and the specificity of material behaviour at the extremely large strains involved, analytical and computational studies have been indispensable for process design, parameter optimization, and the prediction of the microstructures and properties of the ultrafine grained materials produced [2]. The finite element method (FEM) is one of the most important numerical methods that can be used to explain the deformation process during the ECAP [4]. Both 2D and 3D simulations were used to investigate the influence factor on strain homogeneity during ECAP process. It is very important to investigate the material flow during this process, because inhomogeneous strain distributions induced during each billet pass might cause certain heterogeneity in the final microstructure and thus heterogeneity in the mechanical properties of the produced samples [5-8]. Sue et al. indicated that 3D FEM simulation should be used for strain homogeneity description due to the important friction influence on strain distribution in three section planes [9]. Li et al. performed a detailed study in which the influence of the die geometry parameters, the friction conditions, and the material 
model was analysed. They compared predictions obtained by the elastic-perfectly plastic and by the non-linear strain hardening material model and according to their observations the non-linear hardening model results in strain distributions that are more inhomogeneous. Furthermore, they investigated the friction coefficient values in range $\mu=0-0.15$ and concluded that an increase of the friction coefficient, strain hardening and outer die angle result in a certain increase of strain inhomogeneity if no corner gap is formed [10]. Tool geometry is also influential on strain homogeneity. Several numerical studies indicated that rather inhomogeneous strain distributions are obtained for greater values of the outer die angle $\psi$. For instance, for such geometries and frictionless conditions, Suh et al. obtained extremely inhomogeneous distributions while using a perfectly plastic material model [8]. Mendes Filho et al. analysed tool geometries with outer corner angle the in range $\psi$ $=0^{\circ}-60^{\circ}$ while keeping the die angle $\varphi=120^{\circ}$ constant and also concluded that for greater $\psi$ homogeneity decreases [11]. Djavanroodi et al. showed in their research that a lower magnitude of effective strain has been achieved for larger die channel angle $\varphi$ however better strain homogeneity distribution has been obtained [12]. To investigate the influence of ECAP processing routes 3D FEM simulation must be used. Mahallawya et al. used 3D FEM simulations to investigate the influence of routes $A$ and $B c$ for a total of eight passes on strain homogeneity for the selected transverse cross-section. The homogeneity of deformation indicated by microhardness and by FEM results was higher for route $A$ compared with route $B c$ and increases with the number of ECAP passes. The homogeneity in route $A$ was higher than that in route $B c$ by $10 \%$ after 2 passes up to 8 passes [4]. Experimental research of the ECAP routes was also done. It was showed that route Bc out of four different routes produces samples with maximum hardness and reasonably equiaxed microstructure after 5 passes across selected plain perpendicular to the extrusion axis [13]. In route $\mathrm{Bc}$, because of continuous shearing on the three crystallographic planes, the sub-grain boundaries evolve most rapidly into high angle grain boundaries. In route $\mathrm{Bc}$, the two shearing directions lie on planes intersected at $120^{\circ}$. As a result of this duality in the shearing directions, sub-grain bands are developed on repetitive pressings along two separate and intersecting sets of planes and this leads to an evolution of high angle grain boundary which is reasonably equiaxed [13]. In this paper, 3D FEM simulations were used to determine strain inhomogeneity index for whole sample volume and for selected cross-sections. In previous experimental and simulation researches, authors usually investigated strain homogeneity for selected cross-sections. However, for practical use seems very important to determine strain homogeneity for whole processed material volume and at influence cross-section, both at "usable" part of the workpiece, but also at the workpiece back end. Furthermore, to simulate more realistic ECAP process, in this research samples were trimmed after each pass, rotated, and placed back into ECAP die according to each processing route.

\section{3D FINITE ELEMENT SIMULATION}

To study the distribution and homogeneity of the strain accumulated in the specimen made of EN AW 6082 aluminium alloy during ECAP processing, viscoplastic 3D finite element simulation was used. Simulation of the adiabatic isothermal ECAP process was conducted using commercial software QForm. The workpiece was meshed into 207844 nodes tetrahedral finite elements, which is considered sufficient relative to the work volume or even higher than those used in previous works of 2D or 3D FEM simulations [14]. The mesh was automatically re-meshed if the elements became too distorted during the forming process simulations, which provide a great advantage in simulations of the severe plastic deformation processes. Aluminium alloy workpiece was considered as isotropic material. Flow stress curves for aluminium alloy EN AW 6082 were available in the QForm commercial software database. The main aim was to investigate the influence of four main ECAP processing routes and four ECAP passes on strain homogeneity distribution through samples whole volume and for cross-sections $5 \mathrm{~mm}$ and $30 \mathrm{~mm}$ apart from back end, Figure 1a). To simulate ECAP processing routes 3D FEM must be used due to the requirements for sample rotation. ECAP geometry was designed in SolidWorks computer software. Designed ECAP die channels had $15.3 \mathrm{~mm}$ diameter and they intersected at $90^{\circ}$ angle. Outer angle was defined with $3 \mathrm{~mm}$ radius, Figure 1a). According to the analytic expression provided by Iwahashi et al. this tool should be capable to introduce 1.09 equivalent plastic strain in 
ideal conditions [15]. The 3D die and punch are rigid and non-deformable structures. Used punch speed was $1 \mathrm{~mm} / \mathrm{s}$. The workpiece was $80 \mathrm{~mm}$ in height and 15 in diameter, Figure 1b). To simulate realistic ECAP process, after each ECAP pass samples were trimmed on $15 \mathrm{~mm}$ diameter. In realistic condition, the turning process is usually necessary to put samples back in the ECAP tool for a second pass. Because of the turning process, some of the workpiece volume is lost and workpiece is smaller for the subsequent pass. This change of the workpiece volume and length after each pass certainly influence plastic strain distribution. To achieve realistic results each simulation of the sample pass was set to perform in different operation, where 3D workpiece with simulation results was taken from previous pass, trimmed, rotated according to the selected route and finally placed back into ECAP die for the second pass. To prevent samples self-rotation due to the ECAP die outer angle radius, small front part of each sample after each pass at same position also was trimmed.

a)

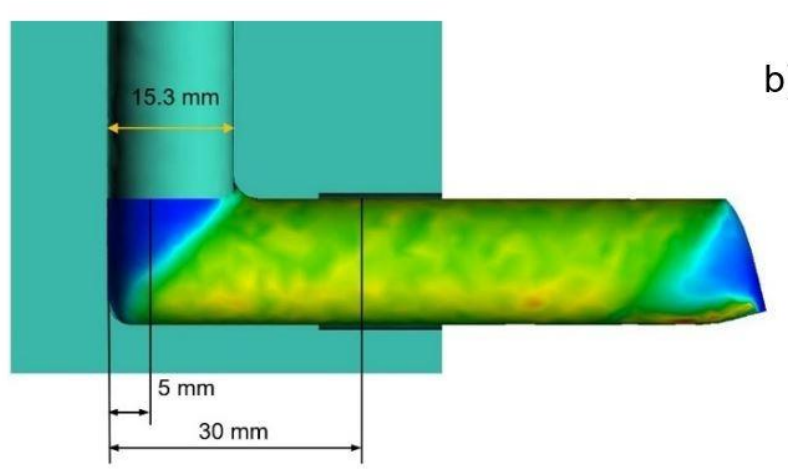

b)

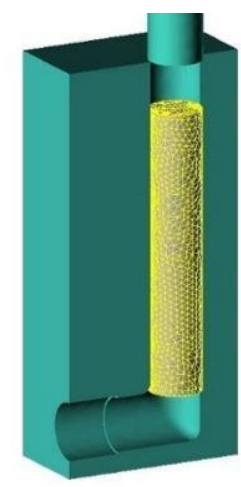

Figure 1 a) ECAP sample after the first pass and selected cross-sections for strain inhomogeneity index determination b) meshed workpiece inside ECAP die

Furthermore, friction is an important factor in ECAP process 3D simulation analysis. Balasundar et al. indicated that the predictions of the shear friction model are correct and hence shear friction model should be used instead of the Coulomb friction model to evaluate the effect of friction in the ECAP process [6]. Li et al. suggested a maximum allowable limit of the friction coefficient of 0.2 to complete the FEM simulations of ECAP with the formation of a reasonable steady-state zone and a good degree of deformation homogeneity [10]. Several authors suggested using a 0.12 friction coefficient for room temperature ECAP and aluminium alloy workpiece [14,16]. Furthermore, friction coefficient value of 0.15 and Levanov model (combined model) is recommended for cold forming of the aluminium alloy in a steel die in QForm software. Therefore, in this paper combined Levanov friction model was used and according to the previous investigation friction coefficient of value 0.12 was selected. The strain inhomogeneity index was described as follows:

$$
C_{i}=\frac{S t \operatorname{dev} \bar{\varepsilon}^{p}}{\operatorname{Avg} \bar{\varepsilon}^{p}}
$$

where $S t \operatorname{dev} \bar{\varepsilon}^{p}$ and $A v g \bar{\varepsilon}^{p}$ are the standard deviation and average value of the effective plastic strain, respectively. The lower value for strain inhomogeneity index means that better strain distribution uniformity for the ECAPed sample.

\section{RESULTS AND DISCUSSION}

According to the simulation results effective plastic strain after one ECAP pass for cross-section 30mm apart from the back end was determined to be average 1.19 which is fairly similar to the analytical expression proposed by Iwahashi et al. [15]. Some higher values of the effective plastic strain were due to the friction influence. The front and end zones of the workpiece (about $20 \%$ of the billet volume) are usually considered not suitable for further use, and it is a major source of material waste [5]. In the previous papers, simulation 
results were usually presented for selected cross-sections due to above mentioned undeformed zones. In this paper, for each ECAP pass and route, strain inhomogeneity index was determined for: whole sample volume, and cross-sections $5 \mathrm{~mm}$ and $30 \mathrm{~mm}$ apart from the workpiece back end, Figure 2. Cross-section at $5 \mathrm{~mm}$ was selected to determine strain inhomogeneity index in sample back end zone. Cross-section at $30 \mathrm{~mm}$ was selected to investigate strain homogeneity in the sample central part.
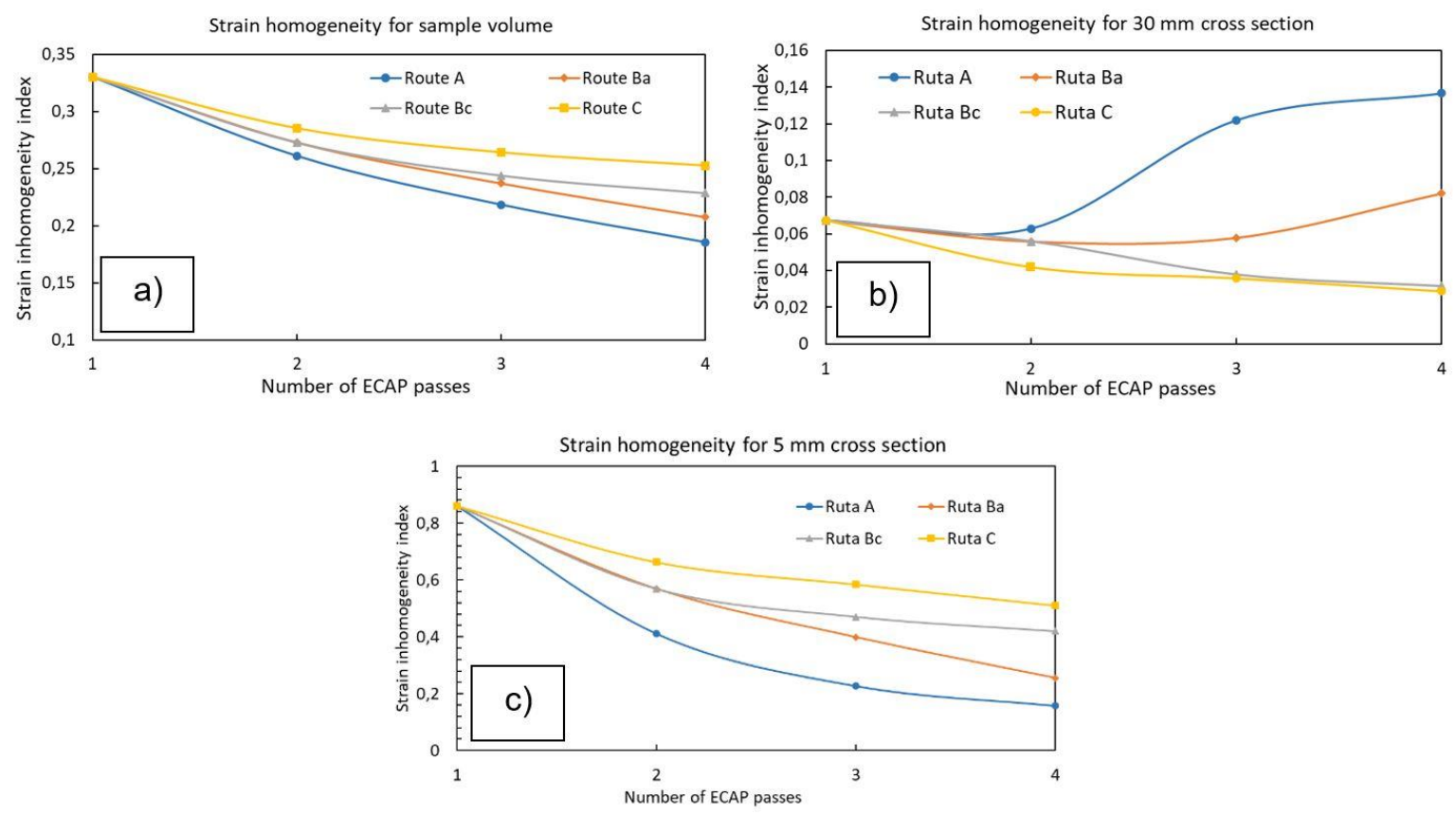

Figure 2 Strain inhomogeneity index values for four ECAP routes and passes: a) sample volume b) crosssection $30 \mathrm{~mm}$ apart from the workpiece back end c) cross-section $5 \mathrm{~mm}$ apart from the workpiece back end

According to the results presented in Figure 2a), strain homogeneity through whole sample volume is significantly improved for all four ECAP routes after four ECAP passes. Furthermore, it seems that routes A and $\mathrm{Ba}$ are more adequate to achieve a lower strain inhomogeneity index through sample volume than routes $\mathrm{C}$ and $\mathrm{Bc}$. Lowest to highest strain inhomogeneity index achieved in the following order: route $\mathrm{A}$, route $\mathrm{Ba}$, route $\mathrm{Bc}$ and finally route $\mathrm{C}$. However, for cross-sections $30 \mathrm{~mm}$ from workpiece back end beginning, route $\mathrm{C}$ and $\mathrm{Bc}$ have lower inhomogeneity index compared with route $\mathrm{Ba}$ and especially route $\mathrm{A}$, Figure $\mathbf{2 b}$ ). For crosssection at $30 \mathrm{~mm}$ for route $A$ and $B a$ strain inhomogeneity index even increases with the third ECAP pass. Results indicated that route $\mathrm{C}$ and $\mathrm{Bc}$ are more adequate if only a homogeneous part of the workpiece material will be used in the possible application. However, if the aim is to use the whole workpiece material volume, route $A$ is much more appropriate for four ECAP pass. This was achieved because route $A$ is more efficient in deformation of the workpiece back end at channels intersection which was indicated with strain inhomogeneity index at cross-section $5 \mathrm{~mm}$ apart from the workpiece back end, Figure 2c). Figure 3 shows effective plastic strain distribution after 4 ECAP passes for route A (Figure 3a)) and route Bc (Figure 3b)). According to Figure 3a), effective plastic strain for route $A$ and cross-section at $5 \mathrm{~mm}$ has much higher values and homogeneous distribution than route $\mathrm{Bc}$ and same cross-section, Figure $\mathbf{3 b}$ ). These small values of the effective plastic strain caused increased strain inhomogeneity index when whole sample volume and crosssection at $5 \mathrm{~mm}$ were observed, Figure 2a) and 2c). According to Figure 3a), effective plastic strain for the route $A$ and cross-section at $30 \mathrm{~mm}$ was inhomogeneously distributed compared with the route $\mathrm{Bc}$ and the same cross-section, Figure $\mathbf{3 b}$ ). This was also confirmed with strain inhomogeneity index for $30 \mathrm{~mm}$ crosssections, Figure $\mathbf{2 b}$ ). Figure 3 indicates that for route Bc (very similar was determined for the route $\mathrm{C}$ ) workpiece back end must be discarded (the front end was already trimmed as explained in section 2). Therefore for practical use of the ECAP processed material usable part of the workpiece should be carefully 
defined and determined. The route $A$ is capable to produce more deformed ECAP workpiece back end but inhomogeneously deformed sample central part. If the route $A$ is used the whole sample can be used for the possible application, however with workpiece material deformed with effective plastic strain in the range from 3 to 5.15 (mean value is 4.35 ) after four ECAP passes for cross-section at $30 \mathrm{~mm}$. If routes $B c$ and $C$ are used, then a very homogeneous central part of the ECAP workpiece can be produced with achieved effective plastic deformation in a range from 4.3 to 5.16 (mean values is 4.8 ) for cross-section at $30 \mathrm{~mm}$. In that case sample back end must be discarded. Therefore, all routes have some advantages, and their selection must be according to possible application.

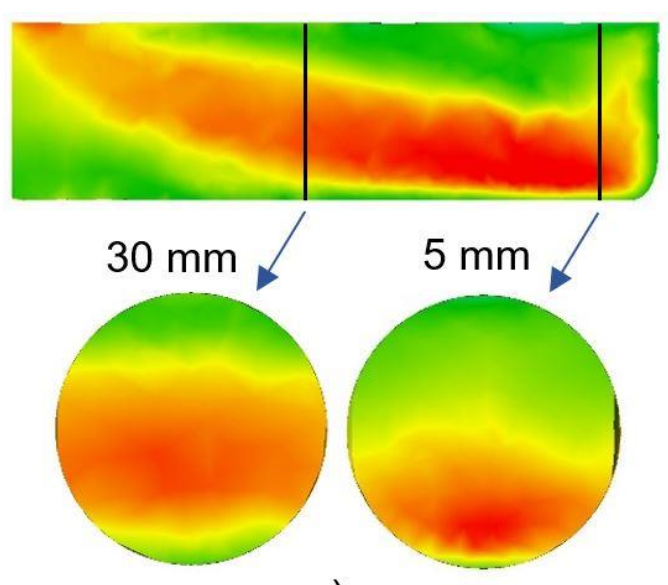

a)

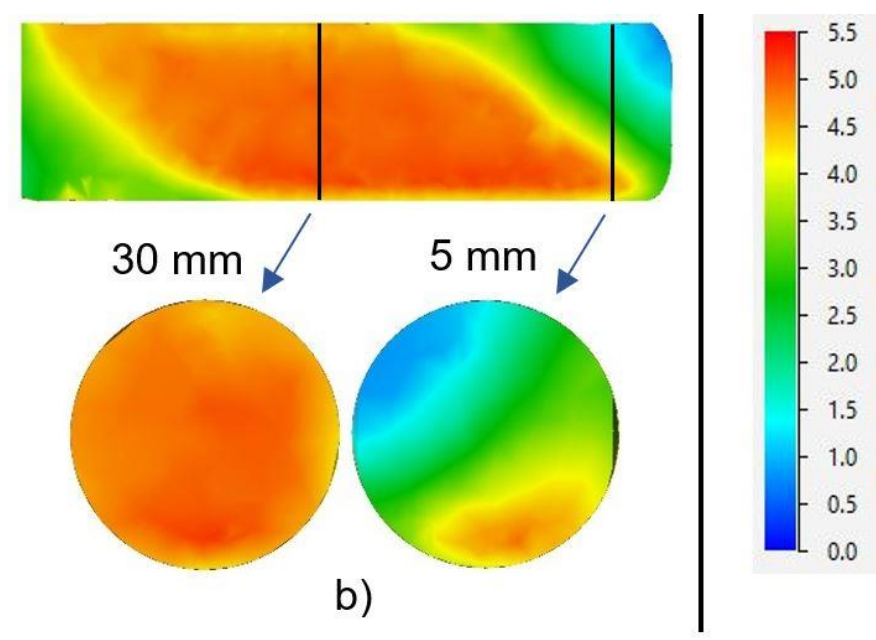

b)

Figure 3 Effective plastic strain distribution after 4 ECAP passes: a) route A cross-sections (longitudinal, 5 $\mathrm{mm}, 30 \mathrm{~mm}$ ) b) route Bc cross-sections (longitudinal, $5 \mathrm{~mm}, 30 \mathrm{~mm}$ )

According to the previous experimental research it was showed that grain flow in ECAP can be associated with routes $\mathrm{A}, \mathrm{Ba}, \mathrm{Bc}$, and $\mathrm{C}$ concerning the plastic deformation in three crystallographic planes $\mathrm{X}, \mathrm{Y}$, and $\mathrm{Z}$. In route $\mathrm{Bc}$ continuous deformation occurs in all three planes and the strain path gets reversed in the successive passes which can cause effective strain homogenization. The reversal of the strain path enables easy formation of shear bands and therefore the grain evolution in all three planes is uniform. On the other hand route $A$ has continuous shearing in $X$ and $Y$ planes but no deformation in the $Z$ plane [13].

\section{CONCLUSION}

According to this research, it was indicated that the distribution and value of the effective plastic strain imposed into ECAP workpiece material strongly depend on ECAP processing routes and the number of passes. This 3D FEM simulation approach provided insight about induced plastic strain into workpiece material when different ECAP routes and four ECAP passes were applied. Simulations results can be used for practical ECAP process utilization. Results indicated that route $\mathrm{C}$ and $\mathrm{Bc}$ are more adequate if only a homogeneous part of the workpiece material will be used in a possible application. However, if the aim is to use the whole workpiece material volume, route $\mathrm{A}$ is more appropriate. For future work and before results application, simulation results verification with experimental work is suggested.

\section{ACKNOWLEDGEMENTS}

QForm simulation software was provided by courtesy of MICAS Simulations Limited, Temple Court, 107 Oxford Road, Oxford, OX4 2ER, U.K. 


\section{REFERENCES}

[1] VALIEV, R., ISLAMGALIEV, R., ALEXANDROV, I. Bulk nanostructured materials from severe plastic deformation. Progress in Materials Science. 2000, vol. 45, pp. 103-189.

[2] VINOGRADOV, A., ESTRIN, Y. Analytical and numerical approaches to modelling severe plastic deformation. Progress in Materials Science. 2018, vol. 95, pp. 172-242.

[3] VALIEV, R.Z., LANGDON, T.G. Principles of equal-channel angular pressing as a processing tool for grain refinement. Progress in Materials Science. 2006, vol. 51, pp. 881-981.

[4] MAHALLAWY, N. EL, SHEHATA, F.A., HAMEED, M.A. EL, AAL, M.I.A. EL, KIM, H.S. 3D FEM simulations for the homogeneity of plastic deformation in Al-Cu alloys during ECAP. Materials Science and Engineering A. 2010, vol. 527, pp. 1404-1410.

[5] EBRAHIMI, M., RAJABIFAR, B., DJAVANROODI, F. New approaches to optimize strain behavior of Al6082 during equal channel angular pressing. Journal of Strain Analysis for Engineering Design. 2013, vol. 48, pp. 395404.

[6] BALASUNDAR, I., RAGHU, T. Effect of friction model in numerical analysis of equal channel angular pressing process. Materials and Design. 2010, vol. 31, pp. 449-457.

[7] GHAZANI, M.S., VAJD, A. Finite Element Simulation of Flow Localization During Equal Channel Angular Pressing. Transactions of the Indian Institute of Metals. 2016, vol. 70, pp. 1323-1328.

[8] SUH, J.Y., KIM, H.S., PARK, J.W., CHANG, J.Y. Finite element analysis of material flow in equal channel angular pressing. Scripta Materialia. 2001, vol. 44, pp. 677-681.

[9] SUO, T., LI, Y., GUO, Y., LIU, Y. The simulation of deformation distribution during ECAP using 3D finite element method. Materials Science and Engineering A. 2006, vol. 432, pp. 269-274.

[10] LI, S., BOURKE, M.A.M., BEYERLEIN, I.J., ALEXANDER, D.J., CLAUSEN, B. Finite element analysis of the plastic deformation zone and working load in equal channel angular extrusion. Materials Science and Engineering A. 2004, vol. 382, pp. 217-236.

[11] MENDES FILHO, A.A.D.A., SORDI, V.L., RUBERT, J.B., FERRANTE, M. The influence of ECAP die channel geometry on shear strain and deformation uniformity. Materials Science Forum. 2008, vol. 584-586 PA, pp. 145150.

[12] DJAVANROODI, F., EBRAHIMI, M. Effect of die channel angle, friction and back pressure in the equal channel angular pressing using 3D finite element simulation. Materials Science and Engineering A. 2010, vol. 527, pp. 1230-1235.

[13] VENKATACHALAM, P., RAMESH KUMAR, S., RAVISANKAR, B., THOMAS PAUL, V., VIJAYALAKSHMI, M. Effect of processing routes on microstructure and mechanical properties of $2014 \mathrm{Al}$ alloy processed by equal channel angular pressing. Transactions of Nonferrous Metals Society of China (English Edition). 2010, vol. 20, pp. 1822-1828.

[14] ABD EL AAL, M.I. 3D FEM simulations and experimental validation of plastic deformation of pure aluminum deformed by ECAP and combination of ECAP and direct extrusion. Transactions of Nonferrous Metals Society of China (English Edition). 2017, vol. 27, pp. 1338-1352.

[15] IWAHASHI, Y., WANG, J., HORITA, Z., NEMOTO, M., LANGDON, T.G. Principle of equal-channel angular pressing for the processing of ultra-fine grained materials. Scripta Materialia. 1996, vol. 35, pp. 143-146.

[16] DE SOUZA, V.A., WATANABE, I., YANAGIDA, A. Numerical estimation of frictional effects in equal channel angular extrusion. Materials Transactions. 2016, vol. 57, pp. 1399-1403. 